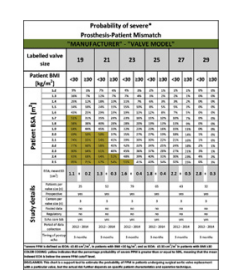

\section{A BIGGER PICTURE FOR VALVE CHARTS}

To the Editor:

In their series of consensus documents, the EACTS-STS-AATS Valve Labelling Task Force has done an excellent job standardizing the labeling of surgical heart valves. The latest paper by Durko and colleagues ${ }^{1}$ provides a well-illustrated framework for determining which physical dimensions should be reported and how these should be defined. One of the key takeaways is an updated format for valve charts. The beauty of the original valve charts is their simplicity; "when the intended valve size is in the red, it is bad." Unfortunately, these charts have been found to be inaccurate for the prediction of individual prosthesispatient mismatch (PPM), even when standardized core laboratory assessment is used to derive the reference effective orifice area (EOA) values. ${ }^{2}$ The inaccuracy is related to the fact that instead of a single value, a range of EOA values is observed for the same surgical heart valve. Therefore, to account for the variance in measured EOA values due to the patients' anatomy and physiology, the authors propose calculating the probability of PPM before implantation, under the assumption that EOA values follow a normal distribution. Although it may be fair to assume that patient and procedural characteristics that affect the calculation of EOA are normally distributed within a study cohort, the reference values for each valve model originate from different study cohorts. Because the population characteristics of the original studies (eg, cardiac output, left ventricular hypertrophy) may confound the resulting reference EOA value, we question the exchangeability of reference values and thus the probability of PPM among different models.

Second, the term "mismatch" in PPM suggests a causal relation between inadequate valve size and adverse events. Although large retrospective studies have demonstrated an association between PPM and survival, the link between PPM and inadequate valve size is unclear. PPM is defined by a cutoff of indexed EOA (EOAi), a measure of relative valve size. The calculation of EOAi relies on various questionable assumptions, including a circular shape of the left ventricular outflow tract, uniform velocity distribution, and body surface area as proportional proxy

\footnotetext{
The Editor welcomes submissions for possible publication in the Letters to the Editor section that consist of commentary on an article published in the Journal or other relevant issues. Authors should: $\bullet$ Include no more than 500 words of text, three authors, and five references. • Type with double-spacing. • See http://jtcs.ctsnetjournals.org/ misc/ifora.shtml for detailed submission instructions. • Submit the letter electronically via jtcvs.editorialmanager.com. Letters commenting on an article published in the JTCVS will be considered if they are received within 6 weeks of the time the article was published. Authors of the article being commented on will be given an opportunity of offer a timely response ( 2 weeks) to the letter. Authors of letters will be notified that the letter has been received. Unpublished letters cannot be returned.
}

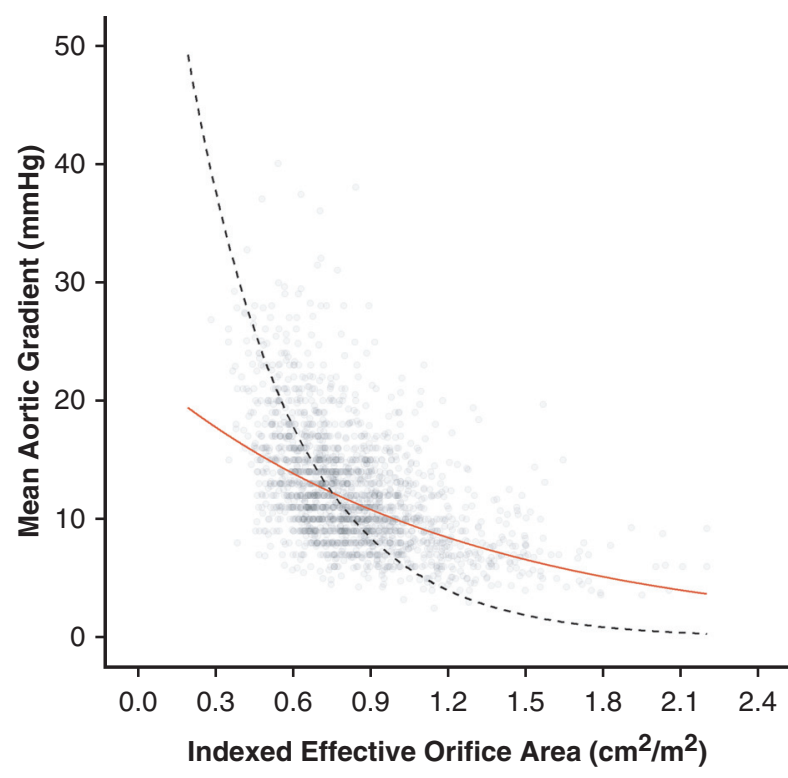

FIGURE 1. Relation between the indexed effective orifice area (EOAi) and mean aortic gradient. In a cohort of exclusively stented bioprosthetic valves $(\mathrm{n}=2171),{ }^{3}$ the exponential decay of the mean gradient (red line) was smaller than the reported curve (black line) by Pibarot and Dumesnil, ${ }^{4}$ on which the current cutoff value of $0.85 \mathrm{~cm}^{2} / \mathrm{m}^{2}$ to classify patients with prosthesis-patient mismatch is based.

of cardiac output. Moreover, as we reported recently, ${ }^{3}$ the categorization of EOAi for the classification of PPM is challenged by a less evident exponential relationship between EOAi and mean aortic gradient (Figure 1) than was stated previously. ${ }^{4}$ Thus, the negative association between PPM and survival might not be due solely to the size of the implanted heart valve.

Finally, because good clinical practice forces us to implant the largest size that fits in the annulus, valve charts insinuate that annular enlargement to further decrease the probability of PPM is beneficial. However, there is no evidence from randomized trials to support such a claim, and annular enlargement potentially increases the operative risk. ${ }^{5}$ Although accounting for variance of reference EOA values is a good step, we believe a more fundamental discussion is needed as to whether valve charts are truly justified in clinical practice. Despite our reservations about valve charts, we thank the authors for their tremendous efforts to standardize valve labeling.

Michiel D. Vriesendorp, $M D$ Robert A. F. de Lind van Wijngaarden, $M D, P h D$ Robert J. M. Klautz, MD, PhD Department of Cardiothoracic Surgery Leiden University Medical Centre Leiden, The Netherlands 
Dr Vriesendorp reported receiving research support from Medtronic. Dr de Lind van Wijngaarden reported no conflicts of interest. Prof Klautz reported receiving research support from Medtronic and consultation and proctoring fees from Medtronic and LivaNova, and participating in speakers' bureaus for Medtronic, LivaNova, and Edwards Lifesciences.

The Journal policy requires editors and reviewers to disclose conflicts of interest and to decline handling or reviewing manuscripts for which they may have a conflict of interest. The editors and reviewers of this article have no conflicts of interest.

\section{References}

1. Durko AP, Pibarot P, Atluri P, Bapat V, Cameron DE, Casselman FPA, et al. Essential information on surgical heart valve characteristics for optimal valve prosthesis selection: expert consensus document from the European Association for Cardio-Thoracic Surgery (EACTS) - the Society of Thoracic Surgeons (STS)-American Association for Thoracic Surgery (AATS) valve labelling task force. J Thorac Cardiovasc Surg. October 6, 2020 [Epub ahead of print].

2. Vriesendorp MD, de Lind van Wijngaarden RAF, Head SJ, Kappetein AP, Hickey GL, Rao V, et al. The fallacy of indexed effective orifice area charts to predict prosthesis-patient mismatch after prosthesis implantation. Eur Heart $J$ Cardiovasc Imaging. 2020;21:1116-22.

3. Vriesendorp MD, Deeb GM, Reardon MJ, Kiaii B, Bapat V, Labrousse L, et al. Why the categorization of indexed effective orifice area is not justified for the classification of prosthesis-patient mismatch. J Thorac Cardiovasc Surg. November 12, 2020 [Epub ahead of print].

4. Pibarot P, Dumesnil JG. Hemodynamic and clinical impact of prosthesis-patient mismatch in the aortic valve position and its prevention. J Am Coll Cardiol. 2000;36:1131-41.

5. Hawkins RB, Beller JP, Mehaffey JH, Charles EJ, Quader MA, Rich JB, et al. Incremental risk of annular enlargement: a multi-institutional cohort study. Ann Thorac Surg. 2019;108:1752-9.

https://doi.org/10.1016/j.jtcvs.2020.11.097

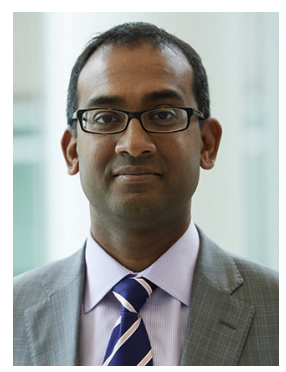

REPLY: ESTABLISHING CLARITY ON VALVE LABELING

Reply to the Editor:

Vriesendorp and colleagues ${ }^{1}$ provide a thoughtful and valid "Letter to the Editor" discussing some of the finer points of the most recent publication from the American Association for Thoracic Surgery, Society of Thoracic Surgeons, European Association for Cardio-Thoracic Surgery valve labeling task force. They have astutely noted the critical concerns with using patient-prosthesis mismatch (PPM) charts, in their current form, without fully incorporating or understanding the methodology used in their derivation. The task force has shared many of these same concerns and focused a significant amount of effort in further elucidating and rectifying these data. ${ }^{2,3}$ The PPM charts with probabilities rather than a binary green (acceptable) or red (not acceptable) designation was intended to account for statistical probabilities with wide variation in clinical scenarios, and thus data that exist in real-world practice. The authors are correct: There are several factors beyond patient size and valve size that contribute to effective valve orifice area. The PPM charts were devised in collaboration with surgeons and valve engineers with the intent of providing cardiac surgeons the opportunity to evaluate a summary of the adjudicated clinical trial data in a concise manner-thus, the compromise to present the data as a percent of patients in the available aggregate dataset who were deemed to have PPM. We did acknowledge the limitations in clinical trial data with potential wide and disparate patient populations. Yet, given all considerations including in vitro static and pulsatile benchtop simulatorderived data, it was thought that the proposed clinical trial data remained the most validated and reliable.

Additionally, as published, the task force has focused on valve sizers and education of our fellow colleagues on the intended design of the valve sizers. These sizers are specific to each individual valve and not interchangeable between manufacturers or even different valves from the same manufacturers. There are 2 sides to the sizers that should both be used, a barrel sizer to measure the tissue annulus diameter and the replica to approximate the anatomic valve fit. $\mathrm{Dr}$ Vriesendorp and colleagues ${ }^{1}$ astutely point out the fallacy of implanting the largest valve possible rather than the appropriate size that is determined by a patient's tissue annulus diameter. The ultimate indexed effective orifice area will be a factor of not only the implanted valve but also the left ventricular outflow tract. Cleveland and colleagues ${ }^{4}$ evaluated the dangers associated with valve oversizing in a recent publication. They clearly noted significant decreases in both effective orifice areas and increased pressure gradients with progressive oversizing of valves, concluding that appropriately sized valves provide optimal hemodynamic performance.

It is clear there is much to investigate and elucidate when it comes to optimal prosthetic valve selection and implant technique. As a task force, we are hopeful that we have made strides in standardization and transparency of data. The ongoing inquiry and work of thoughtful cardiac surgeons, as in the referenced letter, will continue to optimize valve surgery and outcomes for our patients.

Pavan Atluri, MD

Division of Cardiovascular Surgery University of Pennsylvania

Philadelphia, $\mathrm{Pa}$

\section{References}

1. Vriesendorp MD, de Lind van Wijngaarden RAF, Klautz RJM. Letter to the editor: a bigger picture for valve charts. J Thorac Cardiovasc Surg. 2021;161: e371-2. 